\title{
The follow-up care process in pediatric dentistry - part II
}

Mirel TOMA ${ }^{1}$, Florentina RADU ${ }^{2}$, Gabriel CIOCHINDA ${ }^{1}$, Cristina Nicoleta MIHAI $^{1}$, Sorin Nicolae POPESCU ${ }^{1}$, Viorel Stefan PERIEANU ${ }^{1}$, Corina Marilena CRISTACHE ${ }^{1}$, Maria Glencora COSTACHE ${ }^{1}$, Oana EFTENE ${ }^{1}$, Magdalena Natalia DINA ${ }^{1}$, Madalina MALITA ${ }^{1}$, Iuliana BABIUC ${ }^{1}$, Raluca COSTEA ${ }^{2}$, Radu COSTEA ${ }^{1}$, Elena-Cristina MARCOV ${ }^{1}$, Silvia PER ${ }^{1}$, Valentin SAVA ${ }^{1}$, Madalina Violeta PERIEANU ${ }^{1}$

1"Carol Davila" University of Medicine and Pharmacy, Bucharest, Romania

${ }^{2}$ Private dental practice, Bucharest, Romania

\begin{abstract}
-ABSTRACT
Introduction. By follow-up care process is meant an individualized curative-prophylactic active medical method, which supervises, at the initiative of the doctor, categories of healthy persons - exposed to risk factors - or categories of sick persons suffering from certain conditions.

Purpose. In this study, we will refer to the theoretical and practical aspects regarding the necessity of follow-up care in children patients (preschool children, pupils), adolescents and young people, an operation that must be performed by the doctors with specialization and/or competence in pediatric dentistry, by the doctors with specialization in orthodontics and dentofacial orthopedics, by the school doctors, as well as by the simple dental doctors, who perform very regular pediatric dentistry maneuvers.

Material and method. This study was conducted with the help of 23 pedodontists or pediatric dentists in Bucharest.

Results and discussions. The answers obtained by applying the questionnaire created a clear image of the follow-up care system currently existing in Bucharest.

Conclusions. The follow-up care in pediatric dentistry is the most useful active dental care, and in order to have an increased efficiency it is necessary that it is extremely well organized and controlled.
\end{abstract}

Keywords: follow-up care process, pediatric dentistry, temporary dentition, permanent dentition

\section{INTRODUCTION}

As we have already mentioned in the first part of this study, in pediatric dentistry or pedodontics, the follow-up care process is one of the most important factors in carrying out the activity of this very interesting segment of dentistry. Unfortunately, even though the majority of dental practitioners, including those actively involved in all that pediatric dentistry means, are aware of the importance of performing follow-up care processes, it is quite difficult and it becomes increasingly difficult to explain the importance of dispensing certain categories of parents and relatives of children and adolescents, who come, some for 
specialized treatment, others only for emergency treatment, in private pediatric dentistry offices.

And this aspect is quite simple to explain. Many private pediatric dentistry offices in Romania are not in direct contract with the National Health Insurance House, which means that absolutely all the specialized work is not settled through National Health Insurance House, but they must be paid in full by the parents and relatives of the children and adolescents, with whom they presented in these health units, for specialized dental treatment. Basically, here comes the financial factor, which is increasingly invoked by these categories of parents and relatives: they perceive the follow-up care processes of children and adolescents they have accompanied in pediatric dental offices for specialized treatment, as it is about more and more frequent visits to these specialized medical units, visits often considered useless, in which the specialized pedodontics staff does nothing but collect very simply and quickly sums of money which, cumulatively, are huge holes in family budgets.

Another factor quite often invoked is the time factor, the program of pediatric dentists, which is very busy, involves appointments of children and adolescents who came for specialized treatment in the offices, at any time of day, which does not always correspond to the free time of children and adolescents, as well as of their relatives. Specifically, huge efforts are made, in most cases, both by children and adolescents and by their companions (parents or other relatives), in order to reach these pediatric dentist offices, for to ensure a fair and complete specialized treatment.

But these are already issuing on the agenda faced by the pediatric dentistry medical team (pediatric dentist practitioner, office nurse), in the usual activity they carry out during a working day. However, most parents and relatives are aware of the importance of pediatric dentistry treatment not only early established, but also carefully and professionally performed and subsequently monitored, accepting, some quite easily, others much more difficult, this follow-up care process, being willing to undertakes some additional financial efforts, not only for a good maintenance of the oro-dental health of the dento-maxillary system, but also for the health of the whole organism, for the children and/or grandchildren with whom they presented for specialized dental treatment.

\section{PURPOSE}

As we already mentioned in the first part of this material, we consider, extremely interesting, the follow-up care process aims to prevent, combat and recover from chronic diseases, through organized medical surveillance of certain categories of healthy or sick individuals and the application of appropriate medical and social measures; it is a method of prevention, control and recovery, and is therefore a valuable tool for public health (1-5).

But, in the view of any dentist, with reference especially to those who practice this segment of pediatric dentistry, the follow-up care process in pediatric dentistry, more than even on-demand care, must take into account the entire dento-maxillary system and should not be limited to only one condition or category of conditions: for example, rehabilitation of dental caries at the level of temporary dentition and/or permanent dentition, rehabilitation of chronic dental outbreaks, etc. (1-5).

Specifically, starting both from the information presented in the first part of the paper, but also from the aspects mentioned in the introductory part of this second part of the material, we will continue not only the particularization of notions that effectively define the follow-up care process in pediatric dentistry, but also highlight, and especially the implementation of the need for follow-up care for patients of preschool age, then continuing with school age, but also including adolescence and youth. In fact, this desideratum that we discussed is the main goal in conducting this study.

\section{MATERIAL AND METHOD}

As we have already mentioned in the first part of the paper, from a dental point of view, the age of growth is the most important age, being characterized by the coexistence of teeth from temporary dentition in a resorption stage, with the most important teeth from permanent dentition (1-5).

In this age range, 6-12 years, the isolated report of the disease from the temporarily and/or permanently tooth to the other constituent elements of the dento-maxillary system, is of huge importance. During this age range, it is not possible to decide the preservation or extraction of a tooth belonging to the temporary or permanent dentition, without thinking about the consequences of this therapeutic act on the entire dento-maxillary system of the developing individual (15).

When the treatment and/or extraction of a tooth belonging to the temporary or permanent dentition is brought into question, no matter how correct they are from the point of view of the technique used, they can have extremely harmful results, if these acts are not performed and eventually completed with other maneuvers to further ensure a normal development of the dento-maxillary system.

Thus, the pediatric dentist who actively intervenes on a subject aged 6-12 years cannot act even on a simple caries without being trained. This is the only way to 
decide and act in full knowledge, regarding the consequences of the therapeutic act, on the entire dento-maxillary system. Specifically, the pediatric dentist is not allowed to assist passively, consciously or unconsciously, in the appearance and development of abnormalities, in the individuals of the communities where the follow-up care process was applied (1-5).

The pediatric dentist has many methods to perform the follow-up care process with maximum efficiency (15):

- The correct therapy of simple and complicated dental diseases both for the teeth belonging to the temporary dentition and for the teeth that are part of the permanent dentition;

- The correct restoration of the functional shape of the temporary and permanent teeth;

- Extraction of irrecoverable and/or harmful teeth for the body or for the dento-maxillary system;

- Temporary and/or long-term replacement of temporary or permanent dental absences;

- Removal of occlusal obstacles;

- Leading the mandibular-maxillary relationship through mouthguard and inclined planes;

- Leading the recovery of permanently vicious implanted teeth, expansion of the jaws;

- Myogymnastics and functional reeducation;

- Treatment of bad habits and associated parafunctions.

At the same time, regarding strictly the activity of the pediatric dentist, within the follow-up care process carried out in the community he manages, he must include as much of the community in this process as possible. In the follow-up care process that the pediatric dentist conduct in the community he manages (children, adolescents, young people), must take into account not only the disorders with dental profile, but also the psychological structure of the patients, especially in the case of children and adolescents, as well as the degree of education that define the temperament of this type of subjects (1-5). Basically, the success of a quality pediatric dentistry treatment depends on these aspects.

Starting from all these aspects previously mentioned, regarding the follow-up care process, we made a questionnaire consisting of a number of 5 questions, which we applied to a number of 23 dental practitioners, who practice pediatric dentistry and who work mainly in Bucharest, as well as in several cities adjacent to the city of Bucharest. All subjects work in the private sector and are aged between 37 and 63 years, being distributed as follows: 13 dental practitioners were female (56.52\%) and 10 dentists were male (43.48\%) (Fig. 1).

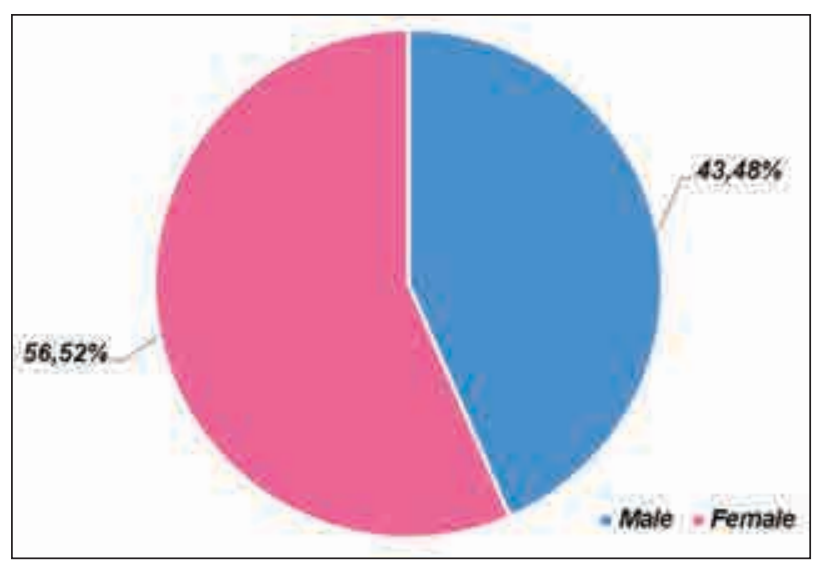

FIGURE 1. Gender distribution of subjects included in study

Next, we will present the questionnaire applied to the 23 subjects.

\section{Questionnaire}

1. How do you appreciate in your activity of pediatric dentistry, the communication you have with the parents and relatives of patients (children, adolescents and young people), which you have in specialized treatment, in the follow-up care process? a. Very good; b. An average bill; c. Very weak.

2. In the age range 6-12 years, the following therapeutic aspects must be considered? a. It is not possible to decide the preservation or extraction of a tooth belonging to the temporary or permanent dentition, without thinking about the consequences of this therapeutic act on the entire dento-maxillary system of the developing individual; $\boldsymbol{b}$. The dental treatment cannot be performed to restore the functional shape of a tooth belonging to the temporary or permanent dentition, without taking into account the consequences on the development of the relationships between the different constituent elements of the dento-maxillary system; c. Is it expressly recommended to remove any tooth belonging to the temporary or permanent dentition and emergency insertion of a dental implant? Correct answers: $\boldsymbol{a}, \boldsymbol{b}$.

3. The attributions of the pediatric dentist in the follow-up care process he has established in the community he manages, consist in? a. The correct therapy of simple and complicated dental diseases both in the teeth belonging to the temporary dentition and in the teeth that are part of permanent dentition; $\boldsymbol{b}$. Correct restoration of the functional shape of temporary and permanent teeth; c. Extraction of irrecoverable and / or harmful teeth for the body or for the dento-maxillary system; $\boldsymbol{d}$. Temporary and/or 
permanent replacement of missing temporary or permanent teeth; e. Removal of occlusal interference? Correct answers: $\boldsymbol{a}, \boldsymbol{b}, \boldsymbol{c}, \boldsymbol{d}, \boldsymbol{e}$.

4. What other attributions the pediatric dentist has in the follow-up care process that he established in the community he manages? a. Conducting the mandibular-maxillary relationship through mouthguard and inclined planes; b. Leading the recovery of viciously implanted permanent teeth; c. Expansion of the jaws; d. Myogymnastics and functional reeducation; e. Treatment of bad habits and associated parafunctions. Correct answers: $a, b, c, d, e$.

5. What factors must be taken into account in the follow-up care process that the pediatric dentist applies to individuals in the community he manages (children, adolescents, young people)? a. The psychological structure of patients, especially in the case of children and adolescents; $\boldsymbol{b}$. The degree of education that defines the temperament of patients (children, adolescents and young people); $c$. The profession of parents and/or relatives? Correct answers: $\boldsymbol{a}, \boldsymbol{b}$.

\section{RESULTS}

The majority of respondents (14 - representing $60.87 \%$ ) consider the communication between the doctor and the parents or relatives of the patients (children, adolescents and young people) as an average one. Only two respondents rate the communication as very good, while the rest of the respondents consider it very poor (Fig. 2).

Regarding the therapeutic aspects that must be considered in the case of treatments for patients aged 6 to 12 years, most practitioners (15 representing $65.22 \%)$ answered correctly: any extraction or treat- ment of temporary teeth should be performed after a careful analysis of the consequences it can have on the development of the dento-maxillary system. The rest of the practitioners consider that only the temporary tooth extraction maneuvers need to be carefully analyzed (Fig. 3).

Concerning the duties of the pediatric dentist in the follow-up care process, the majority of physicians (22 representing 95.65\%) answered correctly (all variants of the answer) only 1 doctor omitted the answer regarding the removal of occlusal obstacles (Fig. 4).

Regarding the attributions of the pediatric dentist in the field of orthodontics and dento-facial orthopedics, only one respondent (representing $8.70 \%$ ) omitted myogymnastics and functional reeducation as well as treatment of bad habits and associated parafunctions, the rest of the respondents correctly ticking all variants of response (Fig. 5).

Regarding the non-dental factors that must be taken into account in the follow-up care process, the majority of study participants (18 representing 78.26\%) answered correctly, namely the psychological structure of patients and the degree of education that defines the temperament of patients aged 6 to 12 years. The rest of the participants wrongly included all the answer options (Fig. 6).

\section{DISCUSSIONS}

It has become very clear that specialists in orthodontics and dento-facial orthopedics have come to the conclusion, over time, that the prevention and treatment of dento-maxillary anomalies cannot be dissociated from the prevention and treatment of dental caries or other diseases, regarding the harmonious development of the dento-maxillary system. Specifically, the specialist in orthodontics and dento-facial ortho-

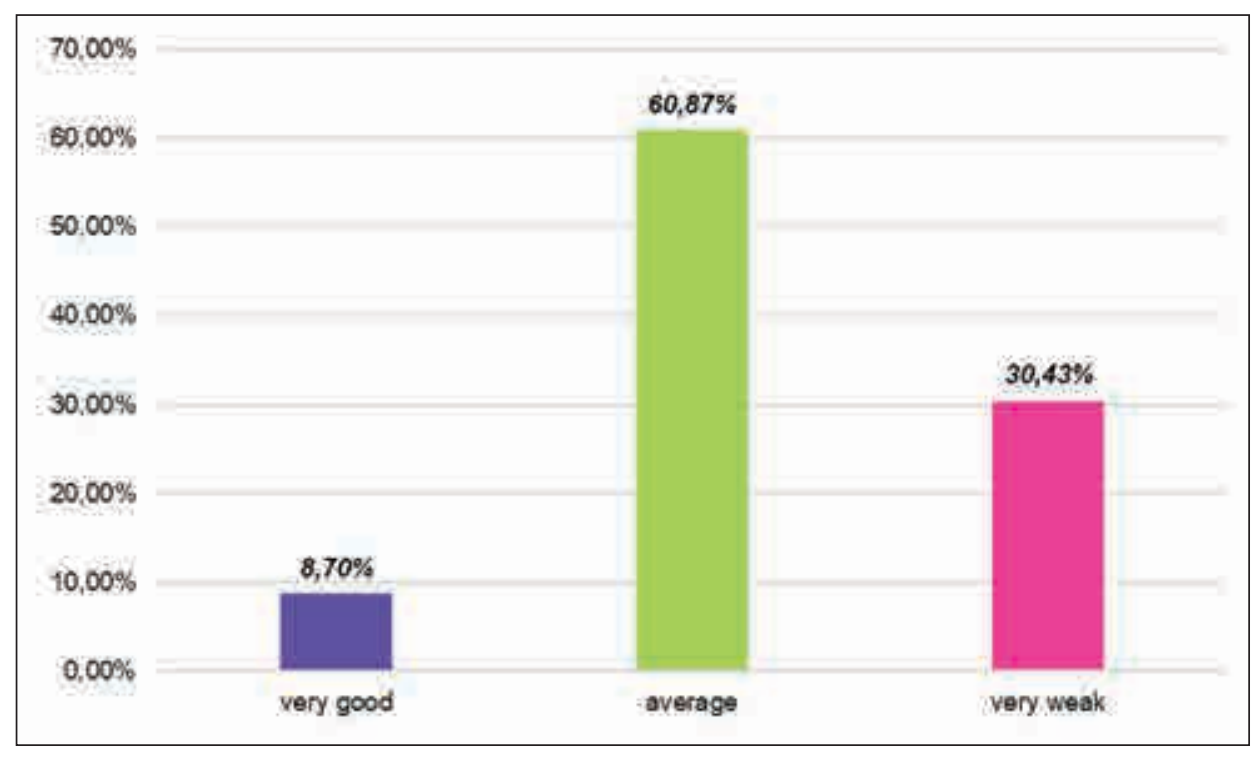

FIGURE 2. Assessment of communication between doctor and parents or relatives 

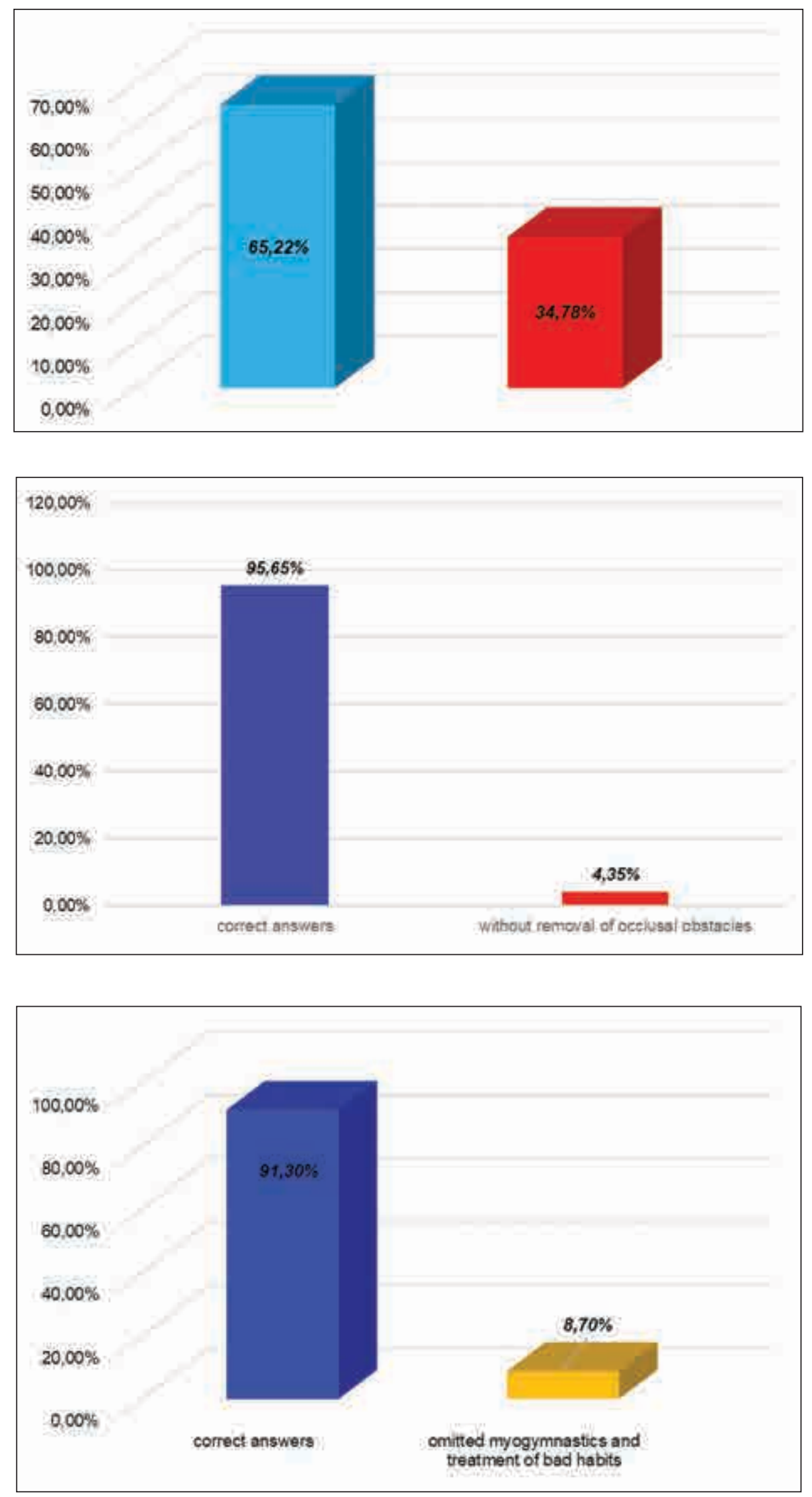

FIGURE 3. Analysis of therapeutic procedures in patients aged 6-12 years

FIGURE 4. Duties of the dentist in the follow-up care process.

FIGURE 5. Orthodontic attributions of the dentist in the follow-up care process pedics cannot effectively carry out a complex and complete clinical activity without the support of pediatric dentists, whose role is limited to both the detection and conservative and/or surgical treatment of dental caries (whether we discuss about temporary dentition, or we are talking about permanent denti- 


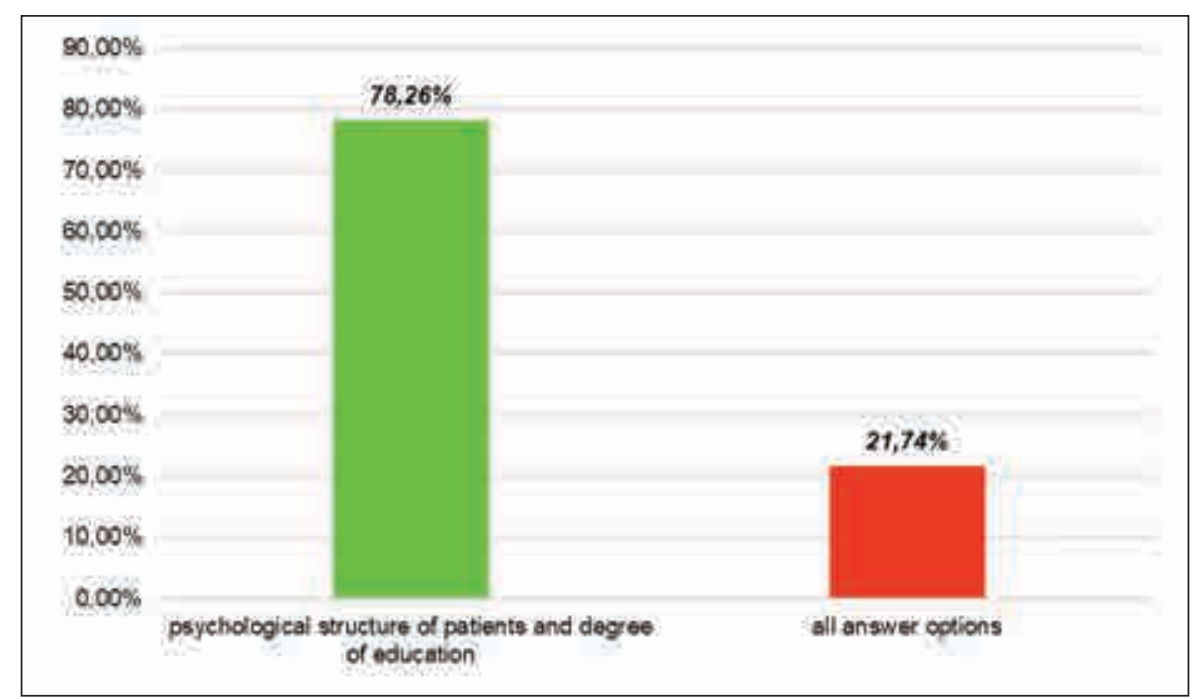

FIGURE 6. Non-dental factors to be taken into account in the follow-up care process tion), but also of diseases of the oral mucosa in children, adolescents and young people.

The pediatric dentist, whether he is or not involved in various follow-up care activities for children, adolescents and young people, must be very well trained so that he can detect, prevent and treat all dental conditions, as well as smaller or larger deviations from the normal development of the dento-maxillary system.

In the follow-up care process an important role is played by the communication between physicians and young patients and parents/carers. Communication can be significantly improved by the practitioner's knowledge of the basic concepts of oral health, as shown by Abreu in 2018 in a study related to orthodontic treatments in children (6).

Similarly, Rozier et al. (2005), in an article on "Parents' satisfaction with preventive dental care for young children", noted that $92 \%$ of parents included in the study positively appreciated frequent communication with the attending physician in a language easy to understand and in $84 \%$ of cases the medical team spent sufficient time to both discussions and treatments (7).

Parents, through their way of being, can influence their children's behavior towards dental treatments. A positive attitude towards oral health will bring the child closer to the dental office and the medical team, turning office visits into a pleasant event beneficial to their own health (8-10). For this reason, communication with parents or carers of young patients is extremely important in transforming the dental office from an environment considered hostile to a friendly environment (8). The treatment plan must take into account the potential cooperation of the young patient, information that can be obtained from parents through questions related to the cognitive level of children (8).

Communication is an essential element in obtaining good results in the case of dental treatments. As stated by the American Academy of Pediatric Dentistry in "Behavior Guidance for the Pediatric Dental Patient" (2015), the communication between physician and children and parents /carers depends on four elements: "the sender, the message, that including the expression and body language of the sender, the context or setting in which the message is send; the receiver, the one to whom the message is addressed" $(8,11)$. The absence of an element or the lack of consistency of the message translates into a mismatch between the message sent and what the person to whom the message is addressed understands $(8,11)$.

The same idea is underlined by the Scottish Dental Clinical Effectiveness Program in "Prevention and Management of Dental Caries in Children - Dental Clinical Guidance" (first edition published in 2010, second edition Full guidance and Guidance in Brief published in 2018). Thus, is underlined the importance of communication between the medical team and the parent/carers throughout all stages of delivering care (12).

Løken et al. (2019), analyzing the association between recall intervals and caries prevalence, concluded that recall intervals can be individualized for each patient, increasing the interval for healthy one and allocating more time and resources for patients who need more dental treatment, evening out the health of the population (13).

\section{CONCLUSIONS}

The pediatric dentist must show a lot of discernment, for programming the oro-dental diseases treated in a subject from the community he monitors, for choosing the most appropriate means of treatment, so that he can meet the already established postulate: "a dento-maxillary system developed harmoniously in a healthy body". 
In the follow-up care process, which the pediatric dentist applies to the individuals in the community he manages (children, adolescents, young people), not only the diseases with a dental profile must be taken into account, but also the psychological structure of the patients, especially in the case of children and adolescents, as well as the degree of education that define the temperament of this type of subjects.

The behavior of the subjects from the communities where the follow-up care process was applied is extremely important in ensuring the success or failure of the pediatric dentist in that community.
At the same time, the pediatric dentist must also have clear pedagogical perceptions, which can guide him in establishing the most effective relationships with subjects in the community where the follow-up care process was applied, especially when talking about children and adolescents.

\section{Acknowledgement}

In this article, all the authors have equal contribution with the first author.

Conflict of interest: none declared Financial support: none declared

\section{REFERENCES}

1. Gall I. Asistența stomatologică. Editura Didactică și Pedagogică, București, 1971.

2. Miyasaki-Ching CM. Elemente clinice de stomatologie. Editura All Educational, București, 2001.

3. Zarnea L. Pedodonție. Editura Didactică și Pedagogică, București, 1993.

4. Burlibașa M, Bilinschi LG, Pavăl B, Eftene O Ionescu I, Mihai A, Perieanu VS, Perieanu MV, Costea RC, Costea R, Tănase G., Malița M, Burlibașa L, Ionescu C.

Preliminary study regarding the necessity of dispensing in the dental medical assistance of pupils, teenagers and young patients. Acta Medica Transilvanica. 2018; 23(1):9698.

5. Sheller B. Challenges of managing child behavior in the 21st century dental setting. Pediatr Dent. 2004;26(2):111-3.
6. Abreu LG. Orthodontics in Children and Impact of Malocclusion on Adolescents' Quality of Life. Pediatr Clin North Am. 2018;65(5):995-1006.

7. Rozier RG, Slade GD, Zeldin LP, Wang $H$. Parents' satisfaction with preventive dental care for young children provided by nondental primary care providers. Pediatr Dent. 2005;27(4):313-322.

8. American Academy of Pediatric Dentistry. Best practice: Behavoir guidance. America`s Pediatric Dentists - The big authority on little teeth. [Online] [Cited: october 13, 2020]. Available at: https://www.aapd.org/ globalassets/media/policies_guidelines/ bp_behavguide.pdf.

9. Feigal RJ. Guiding and managing the child dental patient: a fresh look at old pedagogy. J Dent Educ. 2001;65(12):1369-77.
10. American Academy of Pediatric Dentistry. Policy on the dental home. Pediatr Dent. 2015;37(special issue):24-5.

11. Nutter DP. Good clinical pain practice for pediatric procedure pain: latrogenic considerations. J Calif Dent Assoc. 2009. 37(10):713-8.

12. NHS Education for Scotland. Prevention and Management of Dental Caries in Children. Scottish Dental Clinical Effectiveness Programme. [Online] [Cited: aug 13, 2020]. Available at: https://www.sdcep.org.uk/ wp-content/uploads/2018/05/SDCEPPrevention-and-Management-of-DentalCaries-in-Children-2nd-Edition.pdf.

13. Løken SY, Wigen TI, Wang NJ. Recall intervals in children are individualized and extended. Acta Odontol Scand. 2019; 77(6):468-473. 